\title{
Clinical analysis and prognostic significance of lymphoma-associated hemophagocytosis in peripheral $\mathbf{T}$ cell lymphoma
}

\author{
Wanzhuo Xie • Keyue Hu • Fan Xu • De Zhou • Jingsong He • \\ Jimin Shi • Yi Luo • Jingjing Zhu • Jie Zhang • Maofang Lin • \\ Xiujin Ye $\cdot$ He Huang $\cdot$ Zhen Cai
}

Received: 18 October 2012 / Accepted: 25 November 2012 /Published online: 13 December 2012

(C) The Author(s) 2012. This article is published with open access at Springerlink.com

\begin{abstract}
This study aims to retrospectively analyze the clinical characteristics, treatments, and prognosis of aggressive peripheral $\mathrm{T}$ cell lymphoma (PTCL) patients with a lymphoma-associated hemophagocytosis syndrome (LAHS). We compared the clinical features and the overall survival (OS) rates of 159 PTCL patients with and without LAHS as well as the treatment outcomes of these patients with CHOP (cyclophosphamide, doxorubicin, vincristine, and prednisone) or intensive chemotherapy regimens. We observed that in $23 \%(36 / 159)$ patients PTCL was associated with LAHS. Different subtypes of PTCL in LAHS patients were diagnosed and peripheral $\mathrm{T}$ cell lymphoma, not otherwise specified (PTCL-NOS) was the main subtype (78 \%). The median survival rates of the LAHS and nonLAHS groups were 3 and 16 months, respectively. The elevated rates of serum $\beta 2$-microglobulin, ferritin, fasting triglycerides, and hypofibrinogen levels were higher in the LAHS group, so were bone marrow involvement, liver dysfunction, hepatosplenomegaly, and B symptoms. Three patients who were treated with a plasma exchange had a longer survival time. There was no statistically significant difference in the OS rates between the intensive chemotherapy and CHOP regimen groups $(P>0.05)$. PTCL patients with LAHS had a poorer prognosis. Awareness of the clinical symptoms and laboratory findings are crucial in order to diagnose LAHS in an early stage and repeated biopsies of multiple bone marrows from different locations in those patients without enlargement of superficial lymph nodes
\end{abstract}

W. Xie $\cdot$ K. Hu $\cdot$ F. Xu $\cdot$ D. Zhou $\cdot$ J. He $\cdot$ J. Shi $\cdot$ Y. Luo $\cdot$ J. Zhu $\cdot$ J. Zhang $\cdot$ M. Lin $\cdot$ X. Ye $\cdot$ H. Huang $\cdot$ Z. Cai $(\triangle)$

Department of Hematology, Bone Marrow Transplant Center, The First Affiliated Hospital of Medical School of Zhejiang University, No. 79 Qingchun Road Hangzhou,

310003, Zhejiang, China

e-mail: caizhenBM@163.com are necessary to improve the diagnosis. Intensive chemotherapy due to its severe toxicity was not obviously advantageous for the OS rate compared to the CHOP regimen.

Keywords Aggressive peripheral T cell lymphoma (PTCL) . Lymphoma-associated hemophagocytosis syndrome (LAHS) · Hemophagocytic lymphohistiocytosis (HLH) · Intensive chemotherapy

\section{Introduction}

Aggressive peripheral T cell lymphomas (PTCLs) account for about $7-10 \%$ of non-Hodgkin's lymphomas (NHLs) in Western countries, compared to 20-30 \% NHLs in East Asia $[1,2]$. They are usually characterized by a diffuse disease process in $68 \%$, systemic symptoms in nearly half (45\%), bone marrow involvement (BMI) in a quarter (26\%), and extra nodal diseases in a third (37\%) of the patients [3]. Hemophagocytic lymphohistiocytosis (HLH) is an occasional but severe complication of PTCL in which T cells induce the uncontrolled activation of phagocytosing macrophages, leading to the lymphoma-associated hemophagocytosis syndrome (LAHS) with a high fatality rate [3, 4], and no particular mode of therapy has been satisfactory enough yet for the treatment of PTCL complicated with the LAHS. HLH is a potentially fatal hyperinflammatory condition. It includes genetic (primary) HLH, which is due to mutations in genes important for the cytolytic secretory pathway and causes perforin and granzymes to induce apoptosis in target cells and acquired (secondary) HLH, which occurs as a secondary disorder in association with severe infections, malignancies, rheumatologic disorders, and some metabolic diseases [5]. In non-immunocompromised patients, the main malignancy to be found associated with HLH is T cell 
lymphoma, leading to the LAHS [6]. However, reports of the clinical features of the LAHS are relatively rare, and only some case reports and author's experiences are available $[7,8]$. Thus, we performed a retrospective analysis of clinical features from a large series of patients diagnosed with PTCLs by the criteria of the World Health Organization (WHO) Classification and analyzed the clinical features of LAHS, including the relationship between LAHS and some sub-types of PTCL, the clinical manifestations, some laboratory findings, and overall survival (OS) rates of different treatments in order to elucidate the clinical characteristics, treatments, and prognosis of LAHS patients.

\section{Materials and methods}

\section{Patients}

We consecutively reviewed 159 patients diagnosed with PTCL and who were hospitalized between January 2005 and December 2011 in the Zhejiang University First Affiliated Hospital of the Medical School. All diagnoses were confirmed by histopathological hematoxylin and eosin staining as well as determination of the immunophenotypes according to the WHO Classification 2008 [9]. Complete clinical profiles of all 159 patients who received chemotherapy and finished the follow-up were obtained. Clinical staging and diagnostic methods included a clinical history and physical examination, chest, abdominal, and pelvic computed tomography (CT) scans, full-digital full-body color Doppler ultrasonic diagnostic analyzer examinations as well as bone marrow aspirate and biopsy investigations. Clinical data collected for each patient included lactate dehydrogenase (LDH) and $\beta 2$-microglobulin ( $\beta 2-\mathrm{MG}$ ) levels, immunoglobulin (IG), blood biochemical functions, liver function, blood routine, coagulation functions, tumor markers, ferritin, bone marrow smear, and chemotherapy regimens. We analyzed the differences in laboratory findings and OS rates between PTCL patients with or without LAHS. In addition, we also compared the outcome of the patients who received CHOP or intensive chemotherapy regimens in LAHS patients. Informed consents were obtained from all patients before the collection of patients' information and serum samples for analyses.

Immunohistochemical staining

Sections of all patients were stained with T cell (CD2, CD3, and CD45) and B cell (CD20 and CD79a) markers by using mouse monoclonal antibodies, and disease specificity was confirmed in case that positive staining was observed only with one or more $\mathrm{T}$ cell-specific markers without any positive B cell-specific marker staining. Moreover, CD30 and anaplastic leukemia kinase-1 immunostaining were further used for the differential diagnosis of systemic anaplastic large cell lymphoma, and CD56, CD57, TIA-1, and granzyme B were used as marker for NK/T cell lymphoma diagnosis.

\section{Diagnostic criteria for LAHS}

The diagnostic criteria for LAHS are listed in Table 1 [10].

\section{Clinical staging}

Disease grades were evaluated according to the Ann Arbor Staging System [11] and performance status evaluation based on the Eastern Cooperative Oncology Group scale (0-4) [12]. The patients' international prognostic index [13] scores were determined and used in the survival rate analyses.

\section{Treatment}

Chemotherapy regimens including CHOP (cyclophosphamide $750 \mathrm{mg} / \mathrm{m}^{2}$, day 1 , epirubicin $60 \mathrm{mg} / \mathrm{m}^{2}$ day 1 , vincristine $1.4 \mathrm{mg} / \mathrm{m}^{2}$ day 1 , and prednisolone $100 \mathrm{mg}$ days $1-$ 5) or CHOP-like regimens (idamycin $\left(8 \mathrm{mg} / \mathrm{m}^{2}\right.$ day 1$)$, mitoxantrone $\left(8 \mathrm{mg} / \mathrm{m}^{2}\right.$ day 1$)$, or liposomal doxorubicin (40 $\mathrm{mg} / \mathrm{m}^{2}$ day 1) substituting for epirubicin) were employed. Intensive chemotherapies included ECHOP (CHOP with etoposide 100 mgdays 1-3), CHOP with Ara-C (cytosine arabinoside $200 \mathrm{mg}$ days 1-7), MINE (mitoxantrone $8 \mathrm{mg} / \mathrm{m}^{2}$ days $1-3$, isophosphamide $2.0 \mathrm{~g}$ days $1-3$, mesna $500 \mathrm{mg} / \mathrm{m}^{2}$ days $1-34 \mathrm{~h}$ after each isophosphamide, etoposide $100 \mathrm{mg}$ days 1-3), ESHAP (etoposide $40 \mathrm{mg} / \mathrm{m}^{2}$ days $1-4$, solumedrol $250-500 \mathrm{mg}$ days $1-5$,

Table 1 Diagnostic criteria for LAHS

The primary disease diagnosed as lymphoma

At least five of the following eight criteria mentioned were required Fever

Splenomegaly

Cytopenia $\geq 2$ cell lines

Hemoglobin $<90$ g/L (below 4 weeks $<120$ g/L)

Platelets $<100 \times 10^{9} / \mathrm{L}$

Platelets $<100 \times 10^{9} / \mathrm{L}$

Hypertriglyceridemia and/or hypofibrinogenemia

Fasting triglycerides $\geq 3 \mathrm{mmol} / \mathrm{L}$

Fibrinogen $<1.5 \mathrm{~g} / \mathrm{L}$

Ferritin $\geq 500 \mu \mathrm{g} / \mathrm{L}$

sCD25 $\geq 2,400 \mathrm{U} / \mathrm{ml}$

Decreased or absent NK cell activity

Hemophagocytosis in bone marrow, CSF, or lymph nodes 
Ara-C $2 \mathrm{~g} / \mathrm{m}^{2}$ day 5, platinol $25 \mathrm{mg} / \mathrm{m}^{2}$ days 1-4), DHAP (cisplatin $100 \mathrm{mg} / \mathrm{m}^{2}$ day 1 , dexamethasone $40 \mathrm{mg}$ days 14 , cytarabine $2.0 / \mathrm{m}^{2} \mathrm{q} 12 \mathrm{~h}$ day 2 ), and hyper CVAD (cyclophosphamide $300 \mathrm{mg} / \mathrm{m}^{2} \mathrm{q} 12 \mathrm{~h}$ days $1-3$, doxorubicin $50 \mathrm{mg} / \mathrm{m}^{2}$ day 4 , vincristine $2 \mathrm{mg}$ days 4 and 11 , dexamethasone $40 \mathrm{mg}$ days $1-4$ and 11-14).

\section{Statistics}

OS rates were calculated beginning from the date of diagnosis to death or the last follow-up date. Survival curves were analyzed by the Kaplan-Meier method and log-rank test was used for comparisons between individual clinical features and survival. $\chi^{2}$ test was used to compare the clinical and laboratory data of $\mathrm{T}$ cell lymphomas with and without LAHS. Statistical significance was defined as a $P$ value $<0.05$. All data were processed with the Statistical Package for the Social Sciences 16 software.

\section{Results}

\section{Patient characteristics}

Thirty-six of the 159 PTCL patients were diagnosed with LAHS. In the LAHS group, 28 (78\%) patients had peripheral T cell lymphoma, not otherwise specified (PTCL-NOS), while two $(6 \%)$ were diagnosed with subcutaneous panniculitis-like T cell lymphoma (SCPTCL), three (8\%) with angioimmunoblastic T cell lymphoma (AILT), and three (8\%) with nasal NK/T cell lymphoma (NKTCL). In the non-LAHS group, $64(52 \%)$ patients were diagnosed with PTCL-NOS, five (4 \%) with SCPTCL, 18 (15\%) with AILT, eight $(7 \%)$ with anaplastic large cell lymphoma (ALCL), four (3\%) with enteropathic-type T cell lymphoma, and $24(20 \%)$ with NKTCL. The demographical and clinical characteristics of the patients are listed in Table 2. In the LAHS group the median age was 48 years (range, 1678 years) and 46 years (range, 10-77 years) in the nonLAHS group. All of the patients with LAHS had B symptoms. Most of them were classified into the Ann Arbor III/ IV stage with hepatosplenomegaly and cytopenia. Fifty-six percent (20/36) of the LAHS patients showed combined BMI, which was higher than the BMI in patients without LAHS $(28 \%, 34 / 123)$.

Laboratory findings are listed in Table 3. The elevated rates of $\beta 2-\mathrm{MG}$, ferritin, fasting triglycerides, prothrombin time, and CA125 levels were higher in the LAHS group than in the non-LAHS group $(P<0.05)$, so were hypofibrinogenemia $(P<0.05)$ and liver dysfunction $(P<0.05)$. In contrast, the increased levels of LDH, IG, and renal dysfunctions were not significantly different between the LAHS and the non-LAHS group.
Table 2 Demographics and clinical characteristics of the PTCL: LAHS group versus the non-LAHS group

\begin{tabular}{llll}
\hline & $\begin{array}{l}\text { LAHS group } \\
(n=36)\end{array}$ & $\begin{array}{l}\text { Non-LAHS } \\
\text { group }(n=123)\end{array}$ & $P$ value \\
\hline Median age (years) & 48 & 46 & \\
Range & $16-78$ & $10-77$ & \\
Male/female & $23 / 13$ & $86 / 37$ & \\
III/IV stage & $34(94 \%)$ & $93(76 \%)$ & 0.013 \\
IPI & & & \\
$0-1$ & $4(11 \%)$ & $30(24 \%)$ & 0.087 \\
2-3 & $22(61 \%)$ & $79(64 \%)$ & 0.733 \\
4-5 & $10(28 \%)$ & $14(11 \%)$ & 0.694 \\
B symptoms & $36(100 \%)$ & $94(76 \%)$ & 0.001 \\
Fever & $33(92 \%)$ & $51(42 \%)$ & $<0.001$ \\
Hepatosplenomegaly & $26(72 \%)$ & $28(23 \%)$ & $<0.001$ \\
Cytopenia for at least & $28(78 \%)$ & $16(13 \%)$ & $<0.001$ \\
two cell lines ${ }^{\mathrm{a}}$ & & & \\
With BMI & $20(56 \%)$ & $34(28 \%)$ & 0.002 \\
PTCL-NOS & $28(78 \%)$ & $64(52 \%)$ & \\
SCPTCL & $2(6 \%)$ & $5(4 \%)$ & \\
AILT & $3(8 \%)$ & $18(15 \%)$ & \\
NKTCL & $3(8 \%)$ & $24(20 \%)$ & \\
ETTL & 0 & $4(3 \%)$ & \\
ALCL & 0 & $4(3 \%)$ & \\
\hline
\end{tabular}

$B$ symptoms fever, night sweats, or weight loss, IPI international prognostic index, $B M I$ bone marrow involvement, $P T C L-N O S$ peripheral T cell lymphoma, not otherwise specified, SCPTCL subcutaneous panniculitis-like $\mathrm{T}$ cell lymphoma, AILT angioimmunoblastic $\mathrm{T}$ cell lymphoma, NKTCL nasal NK/T cell lymphoma, ETTL enteropathic type T cell lymphoma, $A L C L$ anaplastic large cell lymphoma

${ }^{a}$ Cytopenia for at least two cell lines with hemoglobin $<90 \mathrm{~g} / \mathrm{L}$ (or below $120 \mathrm{~g} / \mathrm{L}$ for more than 4 weeks), platelet $<10.0 \times 10^{9} / \mathrm{L}$, and neutrophils $<1.0 \times 10^{9} / \mathrm{L}$

Therapeutic results and survival analysis

With the median follow-up of 11 months (range, 179 months), the overall OS rate of the 159 patients was $36 \%$. Statistically significant differences of the OS rates were observed between the LAHS (11\%) and non-LAHS (44\%) group (log-rank $P<0.001$; Fig. 1). The median survival times of the two groups were 3 and 16 months, respectively. Moreover, we compared the OS rates of PTCLNOS patients with and without LAHS and noted a significant difference (log-rank $P<0.001$; Fig. 2). In the LAHS group, statistically significant OS rate differences were not observed comparing elevated IG and normal IG levels (logrank $P=0.504$; Fig. 3 ). The OS rate of LAHS patients treated with a CHOP regimen $(12 \%)$ was lower than the one of patients treated with an intensive chemotherapy $(21 \%)$, but the difference was not statistically significant (log-rank $P=0.545$; Fig. 4). In our study, three LAHS 
Table 3 Laboratory findings of patients with and without LAHS

\begin{tabular}{lrrr}
\hline & LAHS group & \multicolumn{1}{l}{$\begin{array}{l}\text { Non-LAHS } \\
\text { group }\end{array}$} & $P$ value \\
\hline $\mathrm{LDH}>225 \mathrm{U} / \mathrm{L}$ & $22 / 36(61 \%)$ & $64 / 123(50 \%)$ & 0.336 \\
$\beta 2-\mathrm{MG}>2,200 \mu \mathrm{g} / \mathrm{L}$ & $27 / 36(75 \%)$ & $50 / 123(41 \%)$ & $<0.001$ \\
$\mathrm{CA} 125>35 \mathrm{U} / \mathrm{mL}$ & $23 / 28(82 \%)$ & $49 / 96(51 \%)$ & 0.003 \\
Ferritin $\geq 500 \mu \mathrm{g} / \mathrm{L}$ & $21 / 25(84 \%)$ & $15 / 102(15 \%)$ & $<0.001$ \\
Fasting triglycerides & $24 / 32(75 \%)$ & $15 / 93(16 \%)$ & 0.015 \\
$\quad>3 \mathrm{mmol} / \mathrm{L}$ & & & \\
Prothrombin time $>14 \mathrm{~s}$ & $13 / 29(45 \%)$ & $18 / 77(23 \%)$ & 0.03 \\
Fibrinogen $<1.5 \mathrm{~g} / \mathrm{L}$ & $24 / 34(71 \%)$ & $8 / 96(8 \%)$ & $<0.001$ \\
Liver dysfunction $^{\mathrm{a}}$ & $30 / 36(83 \%)$ & $44 / 121(36 \%)$ & $<0.001$ \\
Renal dysfunction $^{\mathrm{b}}$ & $6 / 36(17 \%)$ & $12 / 121(10 \%)$ & 0.264 \\
IG elevation for at $^{\text {least one type }}{ }^{\mathrm{c}}$ & $9 / 21(43 \%)$ & $34 / 90(38 \%)$ & 0.220 \\
& & &
\end{tabular}

$L D H$ lactate dehydrogenase, $\beta 2-M G \beta 2$-microglobulin, $I G$ immunoglobulin

${ }^{a}$ The criteria for liver dysfunction is jaundice, total bilirubin $>17.1$ umol/L, serum albumin $<35 \mathrm{~g} / \mathrm{L}$, alanine aminotransferase, and/or aspartate aminotransferase $>40 \mathrm{U} / \mathrm{L}$

${ }^{b}$ The criteria for liver dysfunction is creatinine $>133$ umol/L and/or blood urea nitrogen $>8.2 \mathrm{mmol} / \mathrm{L}$

${ }^{\mathrm{c}}$ The criteria for IG elevation is $\operatorname{IgG}>16 \mathrm{~g} / \mathrm{L}, \operatorname{IgA}>4 \mathrm{~g} / \mathrm{L}$, and $\operatorname{IgM}$ $>2.3 \mathrm{~g} / \mathrm{L}$

patients were in critical conditions with high fever, hepatosplenomegaly, severe liver dysfunctions, and cytopenia and were given one to three times of plasma exchange before they received chemotherapies. The results showed that the median survival time of these three patients was 5 months, which was longer than that of all other LAHS patients. In summary, LAHS led to worse outcomes not only for all PTCL-affected but also for the PTCL-NOS-affected patients and elevated IG levels were not a significant prognostic factor for LAHS patients.

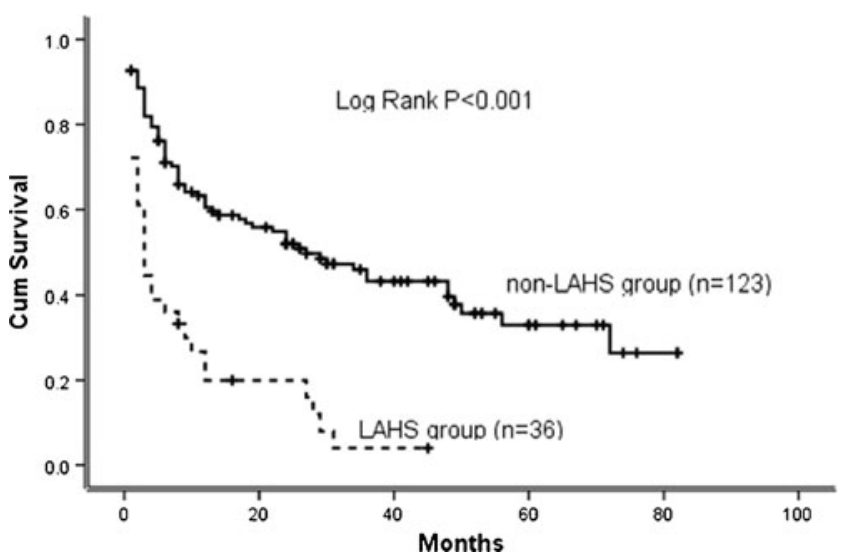

Fig. 1 Kaplan-Meier estimates for the OS rates of 36 PTCL patients with LAHS compared to 123 PTCL patients without LAHS. A statistically significant difference was observed between the two groups (LAHS (11\%) and non-LAHS (44 \%)), $p<0.001$

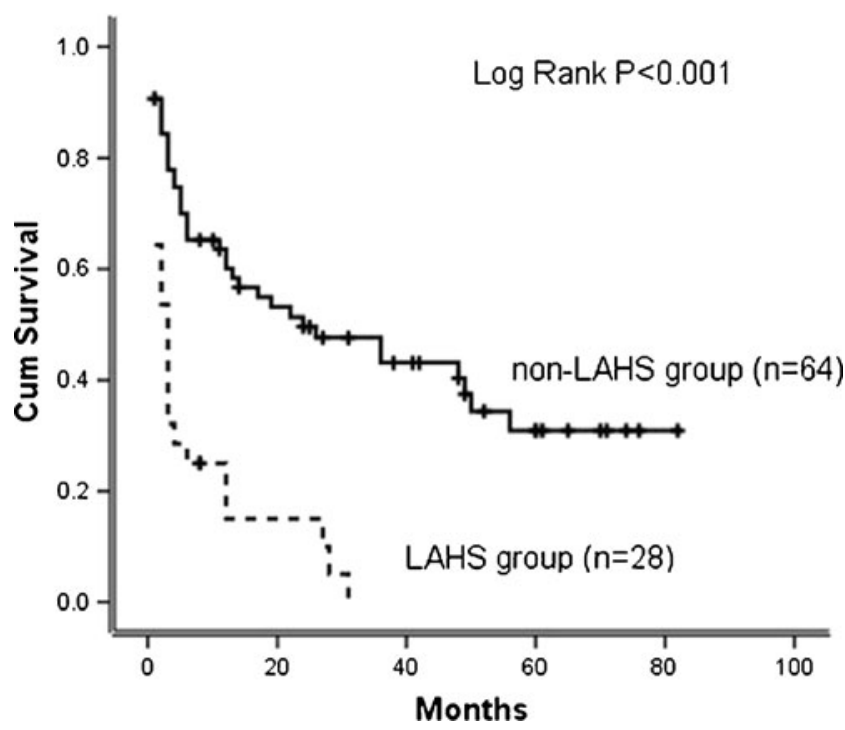

Fig. 2 Kaplan-Meier estimates for the OS rates of 28 PTCL-NOS patients with LAHS compared with 64 PTCL-NOS patients without LAHS. A statistically significant difference was observed between the groups PTCL-NOS patients with LAHS (7 \%) and PTCL-NOS patients without LAHS (41\%), $p<0.001$

\section{Discussion}

HLH is a potentially fatal hyperinflammatory condition caused by a highly stimulated but ineffective immune response [14]. Acquired HLH is associated with malignant diseases, especially lymphomas (LAHS) [6, 15] and most cases of LAHS are associated with T cell or natural killer $(\mathrm{NK}) / \mathrm{T}$ cell lymphoma, while LAHS secondary to B cell

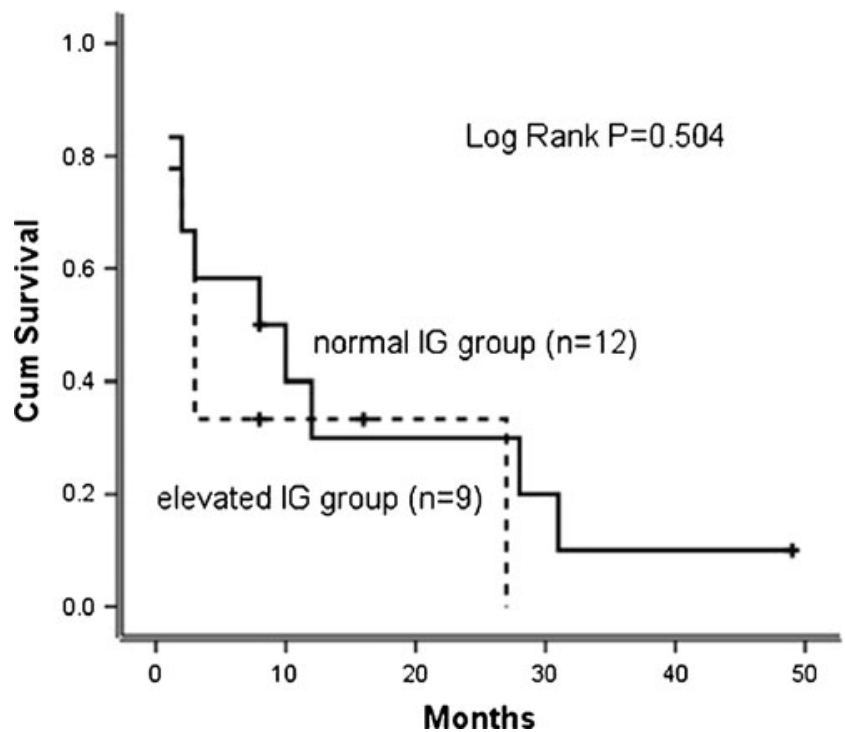

Fig. 3 Kaplan-Meier estimates for the OS rates of LAHS patients with elevated immunoglobulin $(I G)$ levels at initial diagnosis compared to patients with normal IG levels. There was no statistically significant difference between the groups $(P=0.504)$ 


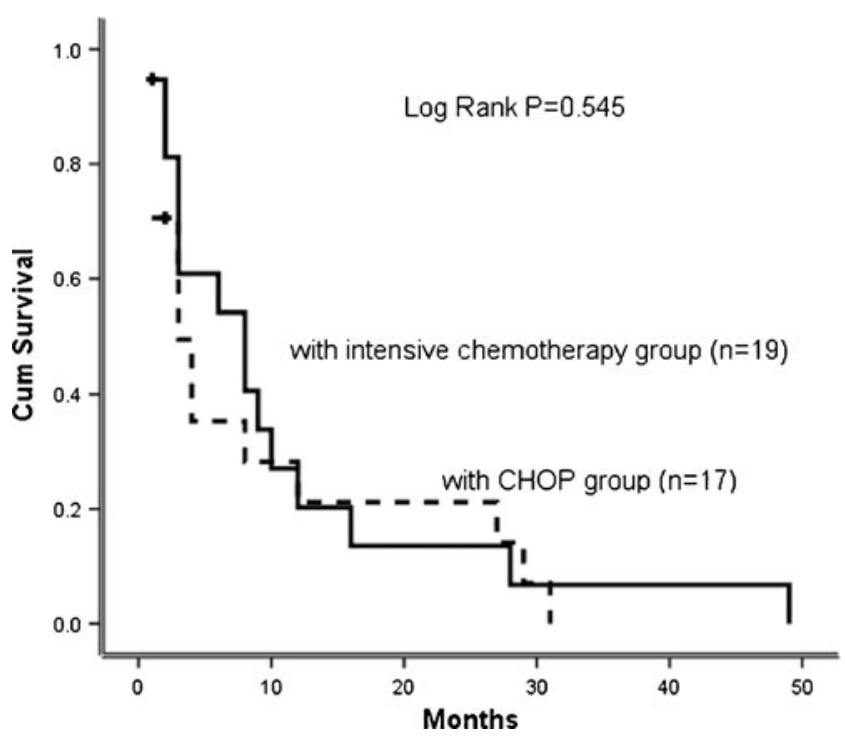

Fig. 4 Kaplan-Meier estimates for the OS rates of LAHS patients with intensive chemotherapy compared to those with a CHOP regimen. There was no statistically significant difference between the two groups $(P=0.545)$

lymphomas are quite rare [15-19]. The frequency of LAHS varies greatly among different clinicopathological entities of PTCLs. Kobayashi et al. [19] reported in pediatric patients from Asia an incidence of $23 \%$ from 22 PTCL patients with LAHS at initial diagnosis and the frequency of HLH was $33 \%(3 / 9)$ in PTCL-NOS, followed by $20 \%(2 / 10)$ in nasal NK/T cell lymphoma. Our data revealed $23 \%$ of 159 PTCL patients with LAHS at initial diagnosis and the frequency of HLH was up to $30 \%(28 / 92)$ in the PTCL-NOS group, $29 \%$ $(2 / 7)$ in the SCPTCL group, $14 \%(3 / 21)$ in the AILT group, and $11 \%(3 / 27)$ in the NKTCL group. In our study, the proportion of LAHS in the PTCL and PTCL-NOS groups was corresponding to Kobayashi's report [19], except that the frequency of HLH in the NKTCL group was lower. Because the number of pediatric patients is small in the literature, further research needs to be done.

We noted that in addition to $\beta 2-\mathrm{MG}$, ferritin and triglyceride increased more remarkably in the LAHS group than in the group without LAHS, which suggested a poor prognosis and further confirmed their importance as indicators for evaluating a $\mathrm{T}$ cell lymphoma prognosis. In contrast, renal dysfunction, increased levels of LDH and IG were irrelevant to whether LAHS was complicated or not. In our study, $56 \%$ of the 36 patients had BMI and $72 \%$ of the 36 patients had hepatosplenomegaly. The percentages in the LAHS group were clearly higher than that in the non-LAHS group (56 vs. $28 \%, P=0.002 ; 72$ vs. $23 \%, P<0.001$, respectively), which indicates that early BMI and hepatosplenomegaly are prominent features in T cell lymphomas with LAHS. Moreover, we detected peripheral lymphadenopathy only in $47 \%$ of the 36 patients with LAHS. It is difficult to diagnose the disease accurately at an early stage without enlargement of superficial lymph nodes. Consequently, repeated biopsies of bone marrow from different locations are necessary and may increase the detection rates.

Unlike cytopenia and liver dysfunction being often mentioned, renal failure in LAHS patients was observed rarely. Renal failure was reported to occur at the advanced stages of HLH and is related to abnormally high concentrations of nephrotoxic IL-6 in the blood serum [20]. In our study, we found renal failures in 17 and $10 \%(P=0.264)$ of the PTCLs patients with and without LAHS, respectively. All of them were classified into Ann Arbor III/IV stages. Though the difference was not statistically significant, we need to be vigilant of creatinine and blood urea nitrogen elevation for early detection of renal failures.

CA125 has been widely used as a tumor marker in monitoring epithelial ovarian cancer. In aggressive NHL, CA125 was found to correlate with stage, tumor bulk, involvement of more than one extra-nodal site, and presence of effusion. Elevated levels of CA125 were found to predict decreased survival and also highly related to high levels of LDH and $\beta 2-M G ~[21-23]$. Contrary to other serum markers such as $\beta 2-\mathrm{MG}$ and $\mathrm{LDH}, \mathrm{CA} 125$ apparently is not released by lymphoma cells and might be secreted by mesothelial cells stimulated via lymphokines derived from NHL [24]. Our data showed that the serum CA125 level increased in $82 \%$ of the patients with LAHS and in $51 \%$ of the patients without LAHS $(P=0.003)$. As it increased in $45 \%$ of the total aggressive $\mathrm{T}$ cell lymphoma patients, we believe that the determination of the serum CA125 level is useful in predicting poor $\mathrm{T}$ cell lymphoma prognoses.

Combination chemotherapy remains the main treatment for T cell lymphoma associated with LAHS. Our data showed that 17 patients received a $\mathrm{CHOP}$ regimen as initial therapy, while some other regimens such as ECHOP, $\mathrm{CHOP}+\mathrm{Ara}-\mathrm{C}$, DHAP, hyper CVAD, MINE, and ESHAP were employed in 19 patients. The estimated OS rates of LAHS patients treated with a CHOP regimen (12\%) was lower than that of patients with intensive chemotherapy ( $21 \%)$, but the difference was not statistically significant (log-rank $P=0.545$ ). The possible explanation for this is that LAHS is usually accompanied by multiorgan and especially cardiac dysfunctions, and intensive chemotherapy might further aggravate organ damage, thereby affecting the survival time. Because intensive chemotherapy is more bone marrow- and immune-suppressive, the toxicity of chemotherapy agents should be considered when patients accept intensive chemotherapies.

The mechanism of LAHS is generally believed to be related to a cytokine storm [25], and based on this theory, some researchers reported that plasmapheresis could achieve good therapeutic outcomes in secondary HLH [26, 27]. Yanagiya et al. [28] noted that a patient with diffuse large B cell lymphoma-associated HLH had his TNF-a, IL- 
6 , and IL-8 serum levels reduced to normal values after plasmapheresis. In our study, three LAHS patients who were given one to three times of plasma exchange before they received chemotherapies had longer survival times. However, like in our retrospective analysis, most of the related reports by now are limited to single cases, and thus more studies are needed to further investigate the efficacy of plasmapheresis.

In conclusion, PTCL patients with LAHS had poorer prognoses than those without and the therapeutic outcome was unsatisfactory. Awareness of the clinical symptoms such as fever, hepatosplenomegaly, cytopenia, and constantly increasing levels of serum $\beta 2-\mathrm{MG}$, ferritin, CA125, and triglyceride is crucial in order to diagnose LAHS early and start life-saving therapies on time. Repeated biopsies of multiple bone marrows from different locations in those without enlargement of superficial lymph nodes are advisable in order to improve the diagnosis. Plasmapheresis as initial therapy is worth trying if the overall outcome of other treatments is unsatisfactory. In general, the treatment of LAHS remains a challenge and an intensive chemotherapy did not led to obvious advantages for the OS rate than a CHOP regimen due to its severe toxicity. Because of the present unsatisfactory therapeutic outcomes, well-designed clinical studies are required to improve the therapeutic procedures.

Acknowledgments This work was supported by the Special Funds for International Cooperation from the National Natural Science Foundation of China (81120108018), the Major Research Plan of the Chinese National Natural Science Foundation (91029740), and the Cultivation Program for Distinguished Talented Persons of Health of Zhejiang, China.

Conflict of interest All authors declare that there is no conflict of interests.

Open Access This article is distributed under the terms of the Creative Commons Attribution License which permits any use, distribution, and reproduction in any medium, provided the original author(s) and the source are credited.

\section{References}

1. Tomita N, Motomura S, Hyo R et al (2007) Comparison of peripheral Tcell lymphomas and diffuse large B-cell lymphoma. Cancer 109:11461151

2. Kojima H, Hasegawa Y, Suzukawa K et al (2004) Clinicopathological features and prognostic factors of Japanese patients with "peripheral T-cell lymphoma, unspecified" diagnosed according to the WHO classification. Leuk Res 28:1287-1292

3. Ascani S, Zinzani PL, Gherlinzoni F et al (1997) Peripheral T-cell lymphomas. Clinico-pathologic study of 168 cases diagnosed according to the R.E.A.L. Classification. Ann Oncol 8:583592

4. Armitage JO, Vose JM, Linder J et al (1989) Clinical significance of immunophenotype in diffuse aggressive non-Hodgkin's lymphoma. J Clin Oncol 7:1783-1790

5. Weitzman S (2011) Approach to hemophagocytic syndromes. Hematology Am Soc Hematol Educ Program 2011:178-183
6. Jaffe ES, Costa J, Fauci AS et al (1983) Malignant lymphoma and erythrophagocytosis simulating malignant histiocytosis. Am J Med 75:741-749

7. Takahashi N, Miura I, Chubachi A et al (2001) A clinicopathological study of 20 patients with T/natural killer (NK)-cell lymphomaassociated hemophagocytic syndrome with special reference to nasal and nasal-type NK/T-cell lymphoma. Int J Hematol 74:303-308

8. Gutierrez A, Solano C, Ferrandez A et al (2003) Peripheral T-cell lymphoma associated consecutively with hemophagocytic lymphohistiocytosis and hypereosinophilic syndrome. Eur J Haematol 71:303-306

9. Swerdlow SH, Campo E, Harris NL et al (2008) WHO classification of tumours of haematopoietic and lymphoid tissues, 4th edn. IARC, Lyon

10. Janka GE, Schneider EM (2004) Modern management of children with haemophagocytic lymphohistiocytosis. Br J Haematol 124:4-14

11. Carbone PP, Kaplan HS, Musshoff K et al (1971) Report of the Committee on Hodgkin's Disease Staging Classification. Cancer Res 31:1860-1861

12. Oken MM, Creech RH, Tormey DC et al (1982) Toxicity and response criteria of the Eastern Cooperative Oncology Group. Am J Clin Oncol 5:649-655

13. (1993) A predictive model for aggressive non-Hodgkin's lymphoma. The International Non-Hodgkin's Lymphoma Prognostic Factors Project. N Engl J Med 329:987-994

14. Janka G (2009) Hemophagocytic lymphohistiocytosis: when the immune system runs amok. Klin Padiatr 221:278-285

15. Falini B, Pileri S, De Solas I et al (1990) Peripheral T-cell lymphoma associated with hemophagocytic syndrome. Blood 75:434-444

16. Cheung MM, Chan JK, Lau WH et al (1998) Primary nonHodgkin's lymphoma of the nose and nasopharynx: clinical features, tumor immunophenotype, and treatment outcome in 113 patients. J Clin Oncol 16:70-77

17. Florena AM, Iannitto E, Quintini G et al (2002) Bone marrow biopsy in hemophagocytic syndrome. Virchows Arch 441:335-344

18. Yamaguchi T, Ashihara E, Inaba T et al (1999) B-cell lymphoma associated with hemophagocytic syndrome. Gan No Japanese 45:439443

19. Kobayashi R, Yamato K, Tanaka F et al (2010) Retrospective analysis of non-anaplastic peripheral T-cell lymphoma in pediatric patients in Japan. Pediatr Blood Cancer 54:212-215

20. Weber J, Yang JC, Topalian SL et al (1993) Phase I trial of subcutaneous interleukin- 6 in patients with advanced malignancies. J Clin Oncol 11:499-506

21. Abd El Gawad IA, Shafik HE (2009) CA 125, a new prognostic marker for aggressive NHL. J Egypt Natl Canc Inst 21:209-217

22. Zidan J, Hussein O, Basher W et al (2004) Serum CA125: a tumor marker for monitoring response to treatment and follow-up in patients with non-Hodgkin's lymphoma. Oncologist 9:417-421

23. Zacharos ID, Efstathiou SP, Petreli E et al (2002) The prognostic significance of CA 125 in patients with non-Hodgkin's lymphoma. Eur J Haematol 69:221-226

24. Abd E, Gawad IA, Shafik HE (2009) CA125, a new prognostic marker for aggressive NHL. J Egypt Natl Canc Inst 21:209-217

25. Tsuda H (1997) Hemophagocytic syndrome (HPS) in children and adults. Int J Hematol 65:215-226

26. Sanada S, Ookawara S, Shindo T et al (2004) A case report of the effect of plasma exchange on reactive hemophagocytic syndrome associated with toxic shock syndrome. Ther Apher Dial 8:503-506

27. Coman T, Dalloz MA, Coolen N et al (2003) Plasmapheresis for the treatment of acute pancreatitis induced by hemophagocytic syndrome related to hypertriglyceridemia. J Clin Apher 18:129-131

28. Yanagiya N, Takahashi N, Nakae H et al (2002) Plasma exchange and continuous hemodiafiltration as an initial treatment for diffuse large B-cell lymphoma-associated hemophagocytic syndrome. Rinsho Ketsueki 43:35-40 